\title{
O REFLEXO FOTO-MOTOR EM PATOLOGIA NERVOSA
}

\section{J. CANDIDO DA SILVA*}

A história do reflexc foto-motor, normal e patológico, está ligada de maneira indissoluvel à cidade de Edimburgo, na Inglaterra. Foi ali que o neurologista Robert Whytt demonstrou, pela primeira vez (1753), que a reação pupilar à luz era um autêntico reflexo. Pertencem a Whytt as primeiras indicações sôbre as prováveis vias do arco reflexo luminoso, tendo êle se referido ac trato ótico como via aferente e ao motor ocular comum como via eferente. Considerando a época remota em que viveu e o pauperismo dos meios de investigação científica naqueles tempos, vetificamos que êsse autor entreviu a questão em todo $c$ seu realismo. Os investigadores do futuro deveriam consagrar o nome de Robert Whytt pela confirmação indiscutivel de suas premissas.

Mais de um século havia decorrido, quando Douglas Argyll Robertson (1869); também neurclogista de Edimburgo, publicou sua notável memória sôbre alteraçóes do reflexo foto-motor na tabes. Pela primeira vez, ficou demonstrado que a reação pupilar à luz pode estar abolida de maneira reflexa, permanecendo normais os movimentos da pupila aos esforços da ccnvergência. Essa dissociação das reações pupilaı es aliada à miose, passou para o domínio da patologia nervosa sob a denominação de sinal de Argyll Robertson, imortalizando o nome do célebre neurclogista.

Este rápido apanhado histórico mostra a intfressante coincidência de ter sido na mesma cidade que se fizeram os prineiros estudos sôbre o reflexo foto-motor e suas alterações, apesar de terem os seus autores vivido em épocas tão afastadas uma da outra.

Depc is dos estudos de Argyll, publicados sob o título "Quatro casos de miose espinhal com observaçōes sôbre o reflexo à luz", muitos trabalhos apareceram $\mathrm{em}$ todo o mundo, engrossando ràpidamente a literatura sôbre o assunto.

Quando Argyll publicou suas observaçôes, a sifilis do sistcma nervosc ainda não tinha sido descrita, portanto êle não podia ter relacionado as alterações do reflexo à luz com a neuro-lúes e sim com a tahes. até então de etiologia desconhecida. Verificou-se pusteriornente que a sífilis nervosa era mais ou menos corrente, sendo a incidencia dos dis-

* Neuro-oftalmologista do Hospital de Juquerí. Trabalho apresentado à Secção de Neuro-Psiquiatria da Associação Paulista de Medicina, em 5 de Agosto de 1943. 
tûrbios pupilares muitc grande em tais casos. Acontece, porém, que êsses distúrbios podem assumir aspetos diferentes dos descritos por Argyll, dando margem a erros de interpretação. Realmente o sinal de Argyll original é muito menos frequente do que as outras alterações do reflexo. Em consequência, generalizou-se o uso da expressão sinal de Argyll a todas as alterações do reflexo foto-motor, mesmo que se apresentem fóra da sífilis.

$O$ intuito dêste trabalho é procurar indicar o que se deve entender por sinal de Argyll e por simples alteração do reflexo fcto-motor, mostrando que os dois tipos de alteração não devem ser confundidos, afinı de preservar o valor semiológico do sinal descrito por Argyll.

\section{SINAL DE ARGYLL ROBERTSON}

Quatro são os elementos clínicos que compõem o sinal de Argyll: 1) Integridade das vias óticas; 2) Miose; 3) Dissociação das reações pupilares, estando abolido o reflexo foto-motor e presente a contração pupilar à convergência; 4 Bi-lateralidade do fenômeno.

$O$ estado normal da acuidade visual pressupõe a integridade da retina e das vias óticas. Sabendo-se que c conteúdo dessas vias é constituido de vibras visuais e fibras pupilo-motoras que caminham juntas desde a retina até o corpo geniculado externo, conclue-se que uma lesão assestada nesse trajeto atingirá a visão (baixa da acuidade ou defeitos do campo) e poderá afetar o reflexo fcto-motor. Sendo normal o estado da visão, devemos interpretar os defeitos do reflexo como expressão de lesão só das fibras pupilo-motoras, situada em qualquer ponto além do corpo geniculado externo, depois que as fibras visuais e pupilomotoras se separam para seguir rumos inteiramente diversos.

A miose é admitida quando as pupilas medem menos de 2 milímetros de diâmetro. Normalmente êsse diâmetro é muito variável, oscilando entre 2 e 5 milímetros segundo os indivíduos. A miose do sinal de Argyll é de tipc paralítico, por destruição das fibras simpáticas que provêm dos núcleos hipotalâmicos e transitam pelo mesencéfalo, em seu trajeto para o centro ć́lio-espinhal de Budge. A concepção de miose paralítica não está baseada em dados anatômicos, mas apenas no senso clínico que não pode aceitar a natureza espasmódica da miose permanente. No sinal de Argyll o diâmetro pupilar mede, às vezes, menos de um milímetro nas duas pupilas. Submetidas à ação da atropina a $1 \%$, as pupilas dilatam-se imperfeitamente ou não se dilatam, fato que na opinião dos autores vem corroborar a idéia de que a miose provem da destruição do simpático ocular em certo ponto do seu trajeto. Entretanto, a prova da atropina é falível, porque existem mioses em paralíticos gerais com sinal de Argyll que cedem totalmente à ação da atropina a $1 \%$ e mesmo da homatropina na mesma titulagem apresentando- 
se as pupilas em midríase máxima ao cabo de 20 minutos após a instilação, como acontece nos indivíduos normais.

A dissociação das reações pupilares deve ser absolutamente nítida no sinal de Argyll, observando-se rigidez total da pupila às excitações luminosas mais intensas e conservação da constrição pupilar acs mais leves movimentos de convergência. A pureza dessa dissociação deve ser mantida, embora o diâmetro pupilar se apresente muito reduzido. A permanência prévia do doențe em câmara escura, seja pelo espaço de horas, não altera o tamanho da pupila, o que constitue ponto importante na diferenciação entre pupilas de Argyll e pupilas miotônicas. Neste último caso, o reflexo pode estar aparentemente abolido, mas ao cabo de 15 minutos de permanência na obscuridade, o diâmetro pupilar apresenta-se visivelmente aumentado, facilitando o desencadeamento do reflexo, mediante forte excitação luminosa. No sinal de Argyll, miose e dissociação parece que surgem simultaneamente e não estão sujeitas à evolução, isto é, mantêm-se inalteráveis até o perícdo terminal da tabes. A rigidez pupilar absoluta (arreflexia pupilar) constitue o término de outras alterações do reflexo foto-motor, diferentes do sinal de Argyll.

O fenômeno de Argyll é bí-lateral, sendo mesmo uma das características assinaladas pelo seu autor nos quatro casos de tabes primitivamente por êle estudados. Com relativa frequência ouvimos falar de Argyll unilateral, mas o fato se prende ao conceito que cada um de nós faz do sinal. Si a simples abolição do reflexo pode ser chamada sinal de Argyll, observamos que a unilateralidade é frequente, mas si considerarmas como Argyll apenas o complexo sintomático que acaba de ser descrito, veremos que o fenômeno é sempre bí-lateral.

A abolição da dilatação pupilar à dor é mais um elemento observado no Argyll. Foi introduzido na patologia pelos neurologistas, sendo, entretanto, de difícil apreciação na prática. Ela traduz a destruição do simpático ocular, jnterrompendo o arco reflexo da dilatação das pupilas às excitações dolorosas periféricas.

Nada sabemos ao certo sôbre a fisiopatologia e a patogenia do sinal de Argyll. Acreditanıcs que a lesão das fibras pupilo-motoras origina a abolição do reflexo à luz e que a destruição do simpático ocular dá lugar à miose. No entanto, a localisação da lesão capaz de explicar essas duas alterações e mais a bi-lateralidade do fenômeno, tem dado margem a discussões e digressões interessantes, entre as quais cumpre destacar os trabalhos de Marina e Lafon ${ }^{1}$ que acreditavam estar a lesão do sinal de Argyll localisada na via centrífuga do arco reflexo, situando-

1. Citado por Lapersonne e Cantonnet - Manuel de Neurologie Oculaire. Masson Cie. Paris 1923. 
a no gânglio ciliar. Os dois autores püblicaram seus estudos antes da fase experimental iniciada por Karplus e Kreidl. Ingzar ${ }^{2}$ explicava a perda do reflexo foto-motor por lesão de meningite crônica atingindo as fibras pupilo-motoras em seu trajeto para os tubérculos quadrigêmeos anteriores, mas essas lesões de modo algum explicavam a miose. Wilson ${ }^{2}$ admitia que as fibras pupilo-motoras eram alcançadas pelas ependimites, propagando-se a toxi-infecção de origem liquidiana por infiltração linfoplasmática, semelhante à que se produz ao nível das raizes posteriores e dá lugar à abolição dos reflexos tendinosos. Merritt e Moore ${ }^{2}$ acham razoável a interpretação de Wilson em relação à paralisia geral, onde a ependimite crônica é habitual, mas na tabes ela é excepcional, não explicando, portanto, o fato de ser o sinal de Argyll mais frequente nesta moléstia do que na paralisia geral. Outros autores acham mais acertada a pcssibilidade de uma lesão focal no ponto em que as fibras foto-motoras e simpáticas são muito vizinhas, no mesencéfalo.

A pequena síntese que acaba de ser feita sôbre a interpretação da patogenia do sinal de Argyll é suficiente para sugerir a pobreza dos estudos anatômicos até agora realizados, permitindo a cada autor aventar hipóteses, às vezes sedutoras, sôbre a patogenia do sinal.

Não deixa de causar extranheza ao espirito do observador clínico, o fato de que o sinal de Argyll possa constituir sintoma importante da tabes e da paralisia geral. Estando as lesōes da tabes situadas no cordão posterior da medula e as da paralisia geral no lóbo frontal principalmente, como podemcs compreender o mecanismo do Argyll por lesões mesencefálicas? Entretanto, à luz dos nossos conhecimentos atuais, não podemos fugir a essa limitação, porque fóra do arco reflexo luminoso não contamcs com outro elemento anatômico para explicar a rigidez pupilar reflexa.

O sinal de Argyll deve possuir, em sua ausência, um substrato capaz de explicar as alterações pupilares pelas mesmas lesōes que dão lugar ao aparecimento da tabes e da paralisia geral. Todas as hipóteses lembradas para definir a patogenia do Argyll, pecam por falta de base anatômica adequada.

Clìnicamente o sinal de Argyll só deve ser assim concebido, quando estiverem presentes os seus quatro elementos componentes. As expressões "falso Argyll", "Argyll verdadeiro", "Argyll invertido", "Argyll complicado", etc., devem ser evitados como causadoras de confusão. Não se trata de questóes de terminologia, mas de salvaguardar o valor semiológico do sinal. Empregado indiferentemente para qualquer distúrbio

2. Cit. por Schaeffer - Le Signe d'Argyll-Robertson. Prèsse Médicale (Setembro, 12) 1934. 
do reflexo toto-motor, o sinal de Argyll torna-se frequente, mesmo fóra da sifilis nervosa, podendo figurar como sintoma de tumores cerebrais e de focos de amolecimento. Seu verdadeiro valor semiológico consiste em indicar neuro-lues parenquimatosa: tabes e paralisia geral.

Nãc é ccmum o sinal de Argyll original. Em 300 paralíticos gerais examinados no Hospital de Juquerí, só observamos 7 doentes com sinal de Argyll, enquanto sobe a $90 \%$ o número dêsses doentes com pupilas patológicas. Pode-se mesmo afirmar que são excepcionais os casos de paralisia geral $\mathrm{c} \cdot \mathrm{m}$ pupilas absolutamente normais.

$\mathrm{Na}$ tabes é maior a frequência do sinal. O Argyll pode preceder a eclosão dos sintomas neurológicos gerais e sua presença parece indicar maior gravidade ao prognóstico da moléstia.

Examinamos em 1929 um paciente cego por atrofia ótica primitiva, que constitue outra forma da neuro-lues parenquimatosa, no qual existia sinal de Argyll com precedência sôbre a atrofia.

$\mathrm{Na}$ lues meningo-vascular sem lesões parenquimatosas, o sinal de Argyll é muito raro, segundo Merritt e Moore (loc. cit.) e, quando presente, indica evolução desses casos para a tabes ou paralisia geral.

A literatura menciona o sinal de Argyll em várias moléstias e afeçōes dc sistema nervoso central. Muito se tem escrito e discutido sôbre o assunto sem que até hoje exista um ponto de vista comum, fato de todo lamentável. $O$ sinal já foi observado até no diabete, mas a possibilidade de presença da sífilis foi discutida nesses casos.

\section{OUTROS DISTÚRBIOS DO REFLEXO FOTO-MOTOR}

Com grande frequência encontramos o reflexo foto-motor alterado, tomando as pupilas os mais bizarros aspetos, como, por exemplo, abolição unilateral do reflex com grande anisocoria, enquanto a outra pupila permanece inteiramente normal; arreflexia de um lado e apenas ligeiros "deficits" da amplitude na outra pupila. O polimorfismo sob o qual se apresentam tais alteraçōes, deu origem às expressōes "Argyll incompleto", "Argyll complicado", "Argyll invertido" e outras já referidas, criando falsa noção sôbre a compreensão do sinal de Argyll. O sinal não se complica, nem se apresenta incompleto; muito menos ainda pode apresentar-se invertido. Desde que não haja miose bi-lateral com disscciação, não se trata de sinal de Argyll. Todos os outros distúrbios devem ser mencionados especificamente, sem procurar englobálos em expressões mal apropriadas.

Tăo corrente tornou-se a pesquiza do reflexo foto-motor na prática neurológica, que Lowenstein ${ }^{3}$ construiu um aparelho especial para cine-

3. Cit. por Jacques Bollack - Les pupilles à 1'état statique. R. Neurologique, $69: 594$ (Junho) 1938. 
matografar o reflexo, projetando depois a película em câmara lenta para melhor estudar o modo de reação e seus defeitos. Conseguiu êsse autor identificar vários tipos normais de reação pupilar. O método de Löwenstein está fadado a representar papel importante, pois permite a apreciação das alterações iniciais do reflexo, cousa impossivel pelos meios comuns de exame.

O reflexo foto-motor é mais rápido nas crianças e nos jovens, perdendo em velocidade à proporção que avança a idade, devido à redução gradativa da elasticidade da iris cujos vasos sofrem modificações. As iris de tonalidade clara (azuis, verdes, etc.) reagem mais intensamente do que as escuras.

No exame do reflexo foto-motor deve-se levar em conta as causas de êrro, colocando o doente nas melhores condições técnicas. Costunamcs observar as seguintes: 1) Adaptação da retina; 2) Relaxamento da convergência; 3) Iluminação fraca e variável; 4)Interferência da acomodação psíquica.

1) Babinski ${ }^{4}$ já tinha observado que o reflexo se torna mais vigoroso quando o doente é conservado 10 ou 15 minutos no escuro. Durante êsse tempo a púrpura retiniana se refaz e, à proporção que ela é secretada, a retina vai se adatando ao escuro, permitindo, ao cabo de alguns minutos, a visão de vultos. Feita a adatação, a retina póde ser excitada com debil fóco de luz. Muitos reflexos tidos ccmo patológicos, podem apresentar-se normais depois da adatação retiniana.

2) Ao iluminar a retina, o doente deve manter o olhar dirigido para um objeto colocado a 5 metros de distância, afim de evitar que a ccnvergência entre em ação e anime a pupila de qualquer movimento extranho ao reflexo, tendo-se o cuidado de examinar cada pupila separadamente, permanecendo a outro oculta.

3) O fóco de luz a ser usado não deve ser fixo. A inconveniência transparece logo do fato de-que uma pupila indiferente a certa jntensidade de luz, pode reagir bem a um fóco luminoso mais vivo. Mesmo quando o reflexo é moroso à luz fraca, deve-se apreciá-lo sob intensidades luminosas mais fortes, afim de sondar o limiar. Temos examinado doentes com o reflexo aparentemente abolido, conseguindo respostas amplas mediante o aumento de iluminação. Não se pode dispensar um reostato no circuito da lampada de reflexo, pois, antes de diagnosticar sua abolição, deve-se ter a certeza de que a pupila não reage às mais altas intensidades luminosas.

4) Durante o exame o doente pode interferir sôbre o reflexo, pela atenção exagerada que presta ao objeto que lhe serve de ponto de referência, criando pelo psiquismo um estado de tensão capaz de modifi-

4. Cit. por Albert Monbrun - Les pupilles à l'état dynamique. R. Neurologique, $69: 603$ (Junho) 1938 . 
car o aspeto normal do reflexo. Os autores designam por acomodação psíquica êsse mecanismo de frenação.

As alterações da reação pupilar à luz podem ser quantitativas e qualitativas, segundo esteja comprometida a amplitude ou a velocidade. $\mathrm{Ob}$ serva-se, em geral, que amplitude e velocidade se modificam paralelamente, mas podem apresentar-se dissociadas. As variaçóes patológicas do reflexo, no espaço e no tempo, constituem materia importante a ser esmiuçada pelo método de Lowenstein, conquanto seja possível apreciá-los pelos meios comuns de exame, quando grosseirás.

Clinicamente, dizemos que o refilexo está alterado, englcbando as duas noções de espaço e de tempo. Verifica-se, no entanto, frequente diversidade das alterações entre um olho e outro, no mesmo paciente, podendo uma pupila apresentar-se patológica e a outra normal, ou ambas patclógicas mas em estados diferentes. De qualquer fórma que se apresentem essas modificaşões, sejam uni ou bi-laterais, elas traduzem sofrimento das fibras pupilo-motoras depois que se separam das fibras sensoriais. Esse fato explica a integridade absoluta da visão em tais casos.

Entre a reaçãc pupilar lenta e a arreflexia medeiam outras variações, como a dissociação (com perda total só do reflexo foto-motor) e a fase que a precede. Nesta última, a reação se desencadeia debilmente mesmo que a solicitemos com forte intensidade luminosa, evidenciando grande redução da area de constrição. Em tais condições, o reflexo mostra-se apenas esboçado, podendo ser confundido com a abclição quando iluminamos a retina com foco debil de luz. Reação lenta, reação esboçada, abolição e arreflexia representam a exteriorização de quatro etapas evolutivas da mesma lesão.

A fisiopatologia e a patogenia dos distúrbic's do reflexo foto-motor tornaram-se claras depois dos memoraveis trabalhos experimentais sôbre as vias da dilatação e da constrição pupilares. Esses trabalhos evidenciaram a inconsistência da concepção clássica do arco reflexo luminosc, no que diz respeito ao seu trajeto retro-mesencefálico.

O esquema clássico (fig. 1) admitia importante sinapse nos tuberculos quadrigêmos anteriores e apresentava êsses centros como zona afeta à constrição pupilar. As fibras pupilo-motoras (7) alí terminadas, iriam ao núcleo parasimpático de Edinger-Westphal por intermédio do feixe teto-espinhal (8). Para explicar a consensualidade do reflexo, o esquema clássico admitia a existência teórica de fibras de asscciação (10) entre os dois núcleos de Edinger-Westphal (9). Esse-esquema que se adata tão bem à fisiologia normal do reflexo foto-motor, não explica os achados da clínica, tais como a abolição unilateral do reflexo. A 
fisiopatologia das alterações unilaterais permanece incompreensível pelo esquema clássico. Onde situar a lesão capaz de abolir o reflexo à luz de um só lado? Como explicar a midríase observada em certcs tumores da região quadrigeminal, em contradição com a função constritora dos tuberculos quadrigêmeos?

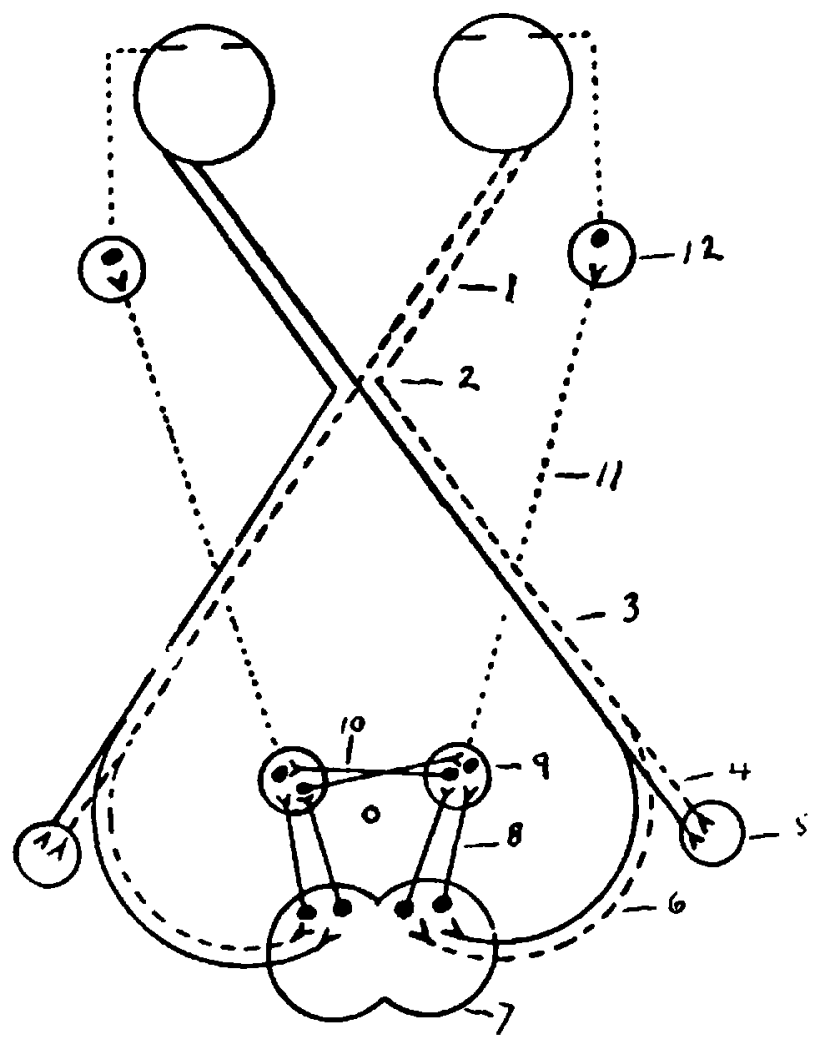

Fig. 1 - Esquema clássico do arco reflexo luminoso. 1 - Nervo ótico direito. 2 -Quiasma. 3 - Fita ótica direita. 4 - Fibras sensoriais. 5 Corpo geniculado externo direito. $6 \rightarrow$ Fibras pupilo-motoras. $7-$ Tuberculo quadrigemeo anterior. $8-$ Feixe této-espinhal. $9-$ Nucleo de Eddinger-Weștphal. 10 - Fibras de associaçäo inter-nucleares. 11 - Fibras eferentes que seguem o III par. 12 - Ganglio cilizr.

Karplus e $\mathrm{Kreidl}^{5}$ realisaram importantes estudos experimentais e chegaram à conclusão de que os quadrigêmeos anteriores são inteira-

5. Cit. por Duke-Elder - Recientes aquisiciones en oftalmologia. Javier Morata, Madrid. 1930. 
mente extranhos à constrição pupilar. Excitados os quadrigêmeos êsses autores observaram, invariavelmente, dilatação da pupila homolateral.

Beattie, Long e colaboradores ${ }^{6}$, repetiram as experiências precedentes e chegaram às mesmas conclusões. Destruiram depcis os núcleos simpáticos hipotalâmicos, já delimitados anteriormente por Karplus e Kreidl e puderam acompanhar o trajeto das fibras degeneradas, verificando que elas se dirigem para a porção retro-messencefálica, passando superficialmente pelos tuberculos quadrigêmeos anteriores, penetrando em seguida na parte médio-lateral do mesencéfalo, para descer pela formação reticulada da protuberância, do bulbo e da medula, terminando no centro cílio-espinhal homolateral. As fibras simpáticas não se cruzam, segundo poude Beattie observar. A excitação do núcleo hipotalâmico de um lado, prcvoca midríase só na pupila do mesmo lado. O trajeto ulterior das fibras simpáticas, depois do centro cílio-espinhal de Budge é bastante conhecido. As fibras eferentes passam pelo gânglio cervical superior, plexo pericarotidiano e alcançam o músculo dilatador da pupila pelos ciliares longes.

Fulton ${ }^{7}$ afirma que os quadrigêmeos anteriores estão definitivamente excluidos do arco reflexo luminoso. A experimentaçăo revelou o primeiro engano do esquema clássico que admitia o tuberculo quadrigêmeo como centro de constrição dentro do arco reflexo luminoso, quando na verdade êle interfere na dilação pupilar e está fóra do arco reflexo.

Os trabalhos experimentais sôbre o trajeto e conexões das fibras pupilo-motoras pertencem a Ranson e Magoun, sobretudo ao primeiro. Ranson ${ }^{8}$ iniciou uma série de excitaçōes sistemáticas da via aferente com o excitador de Horsley Clark, observando que no trecho compreendido entre o quiasma e o corpo geniculado externo (3, fig. 1) a excitação determinava constrição nas duas pupilas. Excitando o braço conjuntival do tuberculo quadrigêmeo anterior (6) e a comissura posterior, obteve também miose bi-lateral, mas ao excitar um pequeno trajeto na região pré-tetal, observou miose só na pupila homolateral, permanecendo inerte a outra pupila. A investigação de Ranson, ccnfirmada mais tarde por Magoun, veiu demonstrar que as fibras que se cruzam no quiasma, tornam a cruzar-se parcialmente na região pré-tetal, terminando no núcleo de Edinger-Westphal ${ }^{9}$ do mesmo lado e não no oposto, como pretendia a crncepção clássica. Os estudos de Ranson criaram base ana1941.

6. Cit. por Lindsay Rea - Neuro-Ophtalmology. C. V. Mosby, St. Louis,

7. Fulton, J. F. - Phisiology of the Nervous System. Trad. espanhola. Ed. Atlantica, Mexico, 1941.

8. Cit. por Schaeffer - Prèsse Médicale (Setembro, 12) 1934.

9. Ranson - The anatomy of the nervous system. W. B. Saunders, Philadelphia 1 vol. 1937. 
tômica capaz de permitir a compreensão das alterações unilaterais do reflexo foto-motor.

Bernheimer ${ }^{10}$ seccionou o quiasma no sentido antero-posterior suprimindo as fibras cruzadas. Mesmo assim obteve o reflexo nas duas pupilas pela excitaçãc luminosa da retina de um lado, provando que as fibras diretas também se cruzam no mesencéfalo e dirigem-se para o núcleo constritor do lado oposto depois de enviar fibras ao núcleo do mesmo lado. Em seguida êsse autor seccionou lateralmente o quiasma e, excitando a retina correspondente, não obteve o reflexo (interrupção total da via aferente), mas ao iluminar a outra retina, observou o reflexo na pupila homolateral e na controlateral, demonstrando, de maneira insofismável, que as fibras diretas vão ter ao núcleo constritor do mesmo lado e ao núcleo do lado oposto.

Os trabalhos de Ranson, Magoun e Bernheimer puzeram em relevo o cruzamento pré-tetal das fibras pupilo-motoras, até então desconhecido, mostrando que essas fibras continuam até os núcleos de Edinger-Westphal e que o feixe teto-espinhal e as fibras de associação inter-nucleares não fazem parte do arco reflexo luminoso, o que constituia o segundc engano do esquema clássico.

Impunha-se, portanto, a necessidade de um novo esquema do arco reflexo, baseado nos fatos experimentais e mais consentaneo com os fatos clínicos. O antigo esquema encontrado nos compendios de neurologia e de oftalmologia tende a ser substituido pelo atual (fig. 2).

Observando o trajeto e a sistematização pré-tetal das fibras pupilomotoras, verifica-se que qualquer lesão que atinja o cruzamento ( 7 , fig. 2), compromete todas as fibras reflexas, dando lugar ao aparecimento da abolição bi-lateral do foto-motor. Uma lesão situada em (8) será responsável pela abolição unilateral do reflexo, deixando íntegro o núcleo constritor (9) que ccntinúa a enviar impulsos à pupila para a sua contração nos movimentos de convergência. Quando a lesão atinge o núcleo de Edinger-Westphal, a pupila entra em arreflexia. $O$ trajeto da via eferente se faz pelo motor ocular comum e gânglio ciliar (sinapse), alcançando o esfincter pupilar pelos ciliares curtos.

A importância clínica das perturbações do reflexo foto-motor transparece logo pela frequência com que são observados: Seu valor semiológico é considerável, apesar de poderem figurar ccmo sintôma de várias moléstias do sistema nervoso.

A neuro-lúes intersticial ocupa o primeiro plano sobretudo a sífilis meníngea. Esse fato explica a enorme frequência (90\%) das mais variadas alterações do reflexo na paralisia geral onde, ao lado das lesões

10. Cit. por Spiegel e Sommer - Oto-neuro-oftalmologia. Francisco Leix, Barcelona, 1937. 
parenquimatesas, existe sempre meningite crônica difusa. A decussão pré-tetal (7) é superficial, podendo ser atingida diretamente pelos processos da meninge, seja por propagação imediata devido à contiguidade

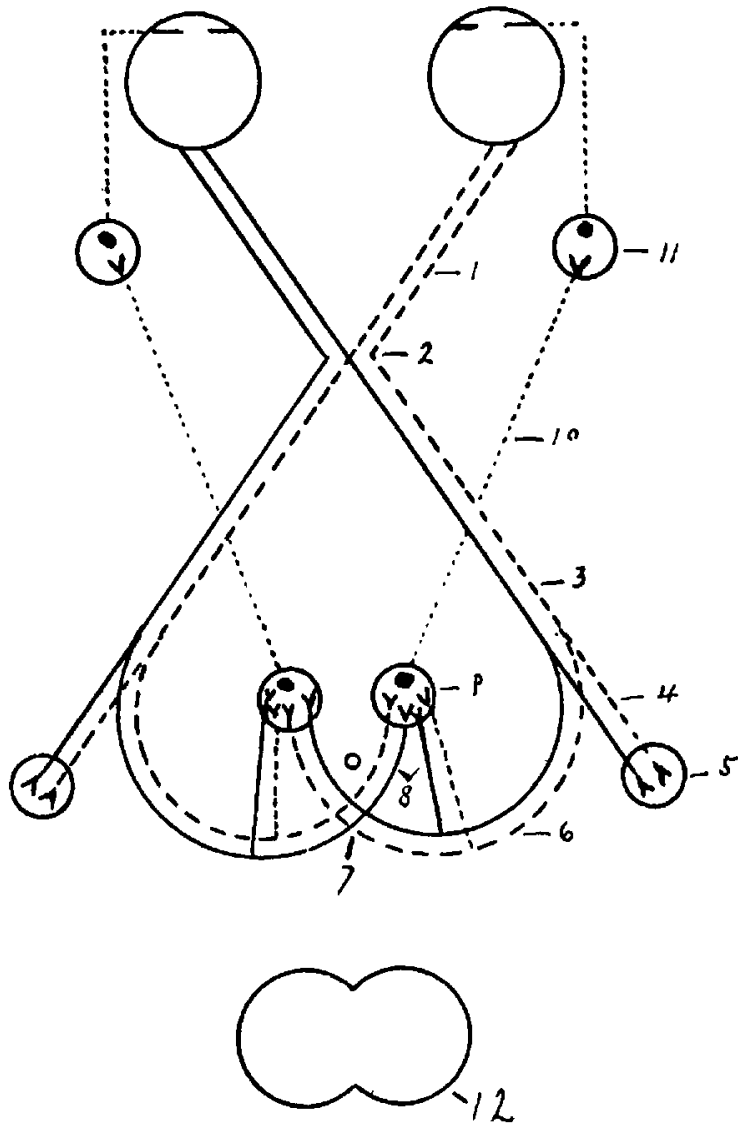

FIg. 2 - Esquema do arco reflexo segundo Behr. $1,2,3,4,5$ e 6 - Mesma legenda da fig. 1. 7 -Decussação pré-tetal, 8 - Trajeto conjunto das fibras dirétas e cruzadas. 9 - Nucleo de Eddinger-Westphal. 10 - I1I0 par. 11 - Ganglio ciliar. 12 - Tubérculos quadrigêmeos anteriores (fóra do arco reflexo).

cu por toxi-infeç̧ão. As alterações do reflexo, de natureza luética, são irreversiveis, mesmc que o tratamento chegue a negativar o líquido e curar a paralisia geral, devido à situação superficial das fibras pupilo-motoras que assim se tornam de extrema vulnerabilidade. $\mathrm{Na}$ sífilis nervosa, as perturbações do reflexo pupilar à luz podem constituir manifestação monosintomática da sífilis indicando pela sua presença, a necessidade do exame do líquido céfalo-raquideano. 
Nas sequelas da encefalite epidêmica pode-se observar o reflexo fotomotor nitidamente alterado, dando impressão de pupilas neuro-luéticas. A diferenciação póde ser feita pela medida do ângulo de convergência. A moléstia de vcn Economo tem eleição pela substância cinzenta, comprometendo com frequência o rúclco de Perlia que funciona como centro periférico da convergéncia. Esse núcleo impar e mediano, situado entre os núcleos laterais do III par, está colocado na visinhança imediata do núcleo de Edinger-Westphal, explicando as modificações reflexas da pupila no post-encefálicos portadores de paresia ou paralisia da convergência. A observação demonstra que a encefalite epidêmica altera de preferência a constrição pupilar à convetgência poupando o reflexo fotomotor (dissociação inversa), mas o contrário pode tambem existir.

$\mathrm{Na}$ síndrome de Adie e na pupilotonia simples, o reflexo pupilar à luz costuma apresentar-se patológico chegando, algumas vezes à abolição. Alajcuanine ${ }^{11}$ recomenda o exame do reflexo pelo microscópio corneano com lampada de fenda depois de colocar o doente 15 minutos na câmara escura, afim de eliminar a possibilidade da existência de movimentos vermiculares da iris. A simples presença dêsses movimentos si bem que rudimentares, não permite o diagnóstico de abolição do reflexo.

$\mathrm{Na}$ esclerose em placas e no zcna oftálmico, já foram assinaladas alterações do reflexo foto-motor. Os tumores cerebrais localisados na visinhança do terceiro ventriculo, do aqueduto e dos tubérculos quadrigêmeos podem provocar distúrbios reflexos da pupila, sendo geralmente acompanhados da síndrome de Parinaud. As lesões vasculares que acarretam fócos de amolecimento da calota mesencefálica, na visinhança do aqueduto dão lugar ao aparecimento de modificações profundas do reflexo foto-motor, com ou sem sindrome de Parinaud.

Em nossas observações possuimos dois doentes portadores de reflexo foto-motor patológico como sintoma isolado. Não fci possivel despistar a existência de sífilis ou qualquer outro fator determinante dêsse sintoma. Um deles apresentava o reflexo reduzido a simples abalo nas duas pupilas e outro tinha acentuada diminurição da ampliturle e da veloc:darle na pupila direita, em forte contraste com a pupila esquerda que se apresentava normal.

\section{CONSIDERAÇOES FINAIS}

As vias que presidem a constrição pupilar sincinética à convergência merecem algumas consideraçóes porque podem ser lesadas isoladamente. Nas dissociações dos mevimentos pupilares, tão frequentemente

11. Alajouanine e Morax - La pupille tonique et ses rapports avec le syndrome d'Adie. Annales d'Oculistique 175:278 (Abril) 1938. 
observadas na clínica, a contração das pupilas à convergência permanece normal, porque as fibras que dirigem êsse movimento procedem da cortex passam pela capsula interna e pedúnculos para se dirigirem depois ao núcleo de Edinger-Westphal. Por outras palavras, enquanto as fibras fotc-motoras transitam pela calota, as fibras da coristrição à convergência passam pelo pé do pedúnculo, explicando porque as lesões que dão lưgar à aboliçāo do reflexo foto-motor não alteram a contração pupilar à convergência sinão depois de alcançarem o núcleo constritor, onde todas as fibras vão terminar (sinapse).

Convergência e contração pupilar são movimentos sinérgicos e associados entre si, observando-se a abolição dêste último quando a convergência está ccmprometida. Podem, no entanto, apresentar-se dissociados patológicamente. A abolição isolada da contraçăo pupilar, com a convergência normal, é fáto conhecido na encefalite epidêmica sobretudo, mas o contrário também é possivel. A clínica demonstra que certos dcentes com paralisia da convergência conservam contração ampla e vigorcsa das pupilas. $O$ impulso cortical de convergência, insuficiente para determinar a adução simultânea dos dois olhos, desencadêia a contração das pupilas de módo nítido.

Nossa experiencia tem demonstrado que o sinal de Argyll é raro, mesmo na paralisia geral. Sua presença parece indicar mau prognóstico. Dos sete casos por nós examinados, seis faleceram, sem que o tratamento tivesse modificado o quadro clínico da moléstia de Rayle. Um ainda continúa no Hospital, tendo sido malarizado duas vezes e recebido tratamento complementar pelos arsenicais, sem modificacăr do quadro. Atualmente está em franca decadência física e psíquica.

As outras alterações do reflexo foto-motor são muito frequentes, chegando mesmo a $90 \%$ na paralisia geral. Elas não parecem indicar gravidade ao prognóstico, figurando apenas como um dos sintomas.

Observamos tambem que o reflexo pupilar à luz póde apresentar-se alterado em casos (muito raros) onde não foi possivel comprovar a existĉncia de qualquer moléstia do sistema nervoso.

Participamos da opinião dos autôres que julgam prejudicial o uso da expressão sinal de Argyll indiferentemente a qualquer disturbio do reflexo fóto-motor. Essa generalisação prejudica a compreensão do verdadeirn valor semiológico dos dois tipos de alteração reflexa das pupilas.

\section{RESUMO}

Depois de rapida exposição historica sobre o reflexo foto-motor e suas alterações, o A. discute o sinal de Argyll Robertson sob seu aspéto clínico e semiológico, procurando demonstrar as conveniências de separar as pupilas de Argyll de quaisquer outras manifestações morbidas do reflexo, afim de preservar o verdadeiro sentido semiológico dessas al- 
terações. O sinal de Argyll póde ser considerado como elemento patognomônico da neuro-lues parenquimatósa (tabes e paralisia geral) e, quando presente na sífilis nervosa mesenquinal, a evolução mostra que esses casos marcham para a tabes ou paralisia geral. O sinal de Argyll deve constituir-se de dissociação das reações pupilares com mióse bi-lateral. As alteraçốes reflexas das pupilas que não apresentarem esses elementos reunidos não devem ser consideradas como sinal de Argyll, sendo mais acertado mencionar apenas os distúrbios pupilares observados. Esses distúrbios variam muito como, por exemplo, abolição unilateral do reflexo, reação lenta em um olho e arreflexia no outro, redução da amplitude com ou sem anisocoria, etc.. Seria impossivel mencionar todas as cambiantes sob as quais se apresenta o reflexo patológico. Essas alterações se encontram na sífilis nervosa mesenquinal, mas pódem figurar como sintoma da encefalite epidêmica, síndrome de Adie e pupilotonia simples, tumores da região quadrigeminal, do aqueduto e da vizinhança do $3 .^{\circ}$ ventriculo.

\section{SUMMARY}

After a brief history of the photomotor reflex and pathclogical alterations, the Author discusses Argyll-Robertson's sign from a clinical and semeiological point of view, emphasizing the necessity of separating this sign from other abnormal deviations of the reflex, with the purpose of maintaining the real semeiological sense of these alterations

Argyll-Robertson's sign can be considered as pathognomonic of parenchymatous neuro-lues (tabes and general paresis) and when the sign is present in mesenchymal neuro-lues, progress towards tabes or general paresis should be expected

Only the dissociation of pupilary reactions with bilateral myosis should be denominated Argyll-Robertson's sign. Alterations of pupillary reactions in which all these elements are not present should not be described as Argyll-Robertson's sign and the alterations should only be mentioned.

These disturbances are considerably variable, such as unilateral abscence of the reflex, retarded reaction of one pupil and arreflexia of the other, reduction of amplitude with or without anisocoria, etc. It would be impossible to mention all the variations of the pathological reflex.

These alterations are present in mesenchymal neuro-lues, but can also be present in epidemic encephalitis, Adie's syndrome and simple tonic-pupil, tumors in the quadrigeminal region, of the aqueduct of Sylvius and about the third ventricle. 